\title{
Estimating the Strain-Rate-Dependent Parameters of the Cowper-Symonds and Johnson-Cook Material Models using Taguchi Arrays
}

\author{
Andrej Škrlec* - Jernej Klemenc \\ University of Ljubljana, Faculty of Mechanical Engineering, Slovenia
}

In order to reduce $R \& D$ costs, a product's behaviour during use is predicted with numerical simulations in the early phases of $R \& D$. If a structure is subjected to high-strain-rate loading this effect should be considered in the material models that are used for the numerical simulations. This article shows how the strain-rate-dependent material parameters can be determined by combining the experimental data with the numerical simulations. The presented methodology is based on the application of Taguchi arrays to find the most appropriate values for the strain-rate-dependent parameters. The presented methodology is applied in a practical case, for which the parameters of the CowperSymonds and Johnson-Cook material models are estimated.

Keywords: strain-rate-dependent material behaviour, finite-element method, explicit dynamics, Taguchi arrays

Highlights

- $\quad$ A procedure for modelling the strain-rate-dependent behaviour of materials is presented.

- The parameters of the Cowper-Symonds and Johnson-Cook material models are estimated on the basis of an impact experiment.

- A simulation plan for estimating the material parameters is developed with the help of Taguchi orthogonal arrays.

\section{INTRODUCTION}

To reduce the costs of a research and development (R\&D) process and optimise the product's design, while ensuring the necessary safety, effectiveness and reliability of the newly developed product, finiteelement (FE) simulations of the product's behaviour under real operating conditions are widely applied. To obtain reasonable simulation results the operating conditions as well as the product's geometry and its material properties must be known. Usually, in the R\&D process the structural loads are assumed on the basis of similar products, are obtained by numerical simulations or are defined by the customer. If we assume that the structural loads resulting from the operating conditions are known, it is the material properties that have the greatest influence on the product's behaviour for a given geometry. If the structure is subjected to extreme mechanical loading conditions (e.g., impacts during crash tests or different burst tests) it is of tremendous importance to consider the strain-rate-dependent material properties when performing a FE simulation.

It is known from the literature [1] that quasistatic loading does not have a significant influence on the material's yield stress and the stress-strain relationship, but this changes if the strain rate increases. The increased values of the strain rate cause an increase in the material's yield stress and change the material's stress-strain behaviour in the plastic domain. Investigations of this effect have been performed by many researchers over the last century, like Hopkinson, Charpy, Taylor [1], Zerilli, Armstrong, Johnson [2], [3], etc. In the last 20 years, strain rate influence on material behaviour is still interesting for researchers like El-Magd [4], Zhao and Gary [5], Huh et al. [6] to [8], etc.

When using the explicit dynamic FE code to simulate extreme loading conditions, such as impact phenomena, the material models that consider the strain-rate dependency of the material's plastic curve are commonly applied. The three most commonly applied material models in researches [9] to [15] that consider the strain-rate effects are: Cowper-Symonds, Johnson-Cook, and Zerilli-Armstrong. Since the Cowper-Symonds and Johnson-Cook material models are simpler than the Zerilli-Armstrong material model, we considered only the former two models in our research. The main difference between them is how they account for the strain-rate effects. Consequently, the number of material parameters that describe the plastic stress-strain relationship with the strain-rate effects is different ([16] and [17]):

- Yield stress according to the Cowper-Symonds material model:

$$
\sigma_{y}=\left(\sigma_{0}+\beta \cdot \frac{E_{t} \cdot E}{E-E_{t}} \cdot \varepsilon_{e f f}^{p}\right) \cdot\left[1+\left(\frac{\dot{\varepsilon}}{C}\right)^{1 / P}\right]
$$


- Flow stress according to the Johnson-Cook material model [3]:

$$
\begin{aligned}
& \sigma_{\text {flow }}=\left[\sigma_{0}+B \cdot\left(\varepsilon_{\text {eff }}^{p}\right)^{n}\right] . \\
& \cdot\left[1+c \cdot \ln \left(\frac{\dot{\varepsilon}^{p}}{\dot{\varepsilon}_{0}}\right)\right] \cdot\left(\frac{T-T_{\text {room }}}{T_{\text {melt }}-T_{\text {room }}}\right)^{m},
\end{aligned}
$$

where $\sigma_{0}$ is the reference yield stress, $E$ is the material's elastic modulus, $E_{t}$ is its tangent modulus, $\beta$ is the hardening coefficient, $\varepsilon_{\text {eff }}^{p}$ is the effective plastic strain, $\dot{\varepsilon}$ is the strain rate and $\dot{\varepsilon}_{0}$ is the reference strain rate. $C$ and $P$ are the strain-rate parameters of the Cowper-Symonds material model; $B, n, c$ and $m$ are the strain- and strain-rate-dependent parameters of the Johnson-Cook material model. The Johnson-Cook material model considers the influence of temperature on the stress-strain behaviour, but not the CowperSymonds material model. However, the temperature effects can be omitted from the Johnson-Cook material model if its parameter $m$ is set to zero. The temperature influences can be omitted from the Johnson-Cook material models if they do not influence the material behaviour. The Cowper-Symonds and Johnson-Cook models are the most commonly applied material models when performing explicit dynamic simulations up to moderate strain rates, (i.e., up to $\dot{\varepsilon}=10^{4}$ ) ([14] and [15]), at which the changing temperature does not have a significant influence.

The main problem, linked to the material parameters that consider the strain-rate effects, is that they cannot be simply measured and determined, thus they are empirically determined through special experimental and optimisation processes ([9] to [13]). For the above-mentioned material models the parameters that consider the strain-rate dependence were investigated for many different materials. In the literature, their typical values for mild steel ([9], [10] and [11]), high-yield-strength steel [12], aluminium alloys [13], titanium alloys [13], etc. can be found. Since, on the other hand, no link between the strainrate parameters and the chemical composition of the material was found, these parameters should be identified individually for each material under consideration.

In this article we will compare the performance of Cowper-Symonds and Johnson-Cook material models when applied for simulating the impact of a ball on a thin steel plate. The parameters of the two material models, which cannot be estimated from the tensile test, were determined from the impact experiments using the LS-DYNA explicit FE code that was combined with a Taguchi array to reduce the numerical processing effort. The article is structured as follows. After the introductory section and the theoretical background, the experimental arrangement and the experimental results are presented. The article continues with a presentation of the results and their discussion and ends with a concluding section and a list of references.

\section{THEORETICAL BACKGROUND}

\subsection{Applied Material Models}

In this article two material models (i.e., the CowperSymonds model and a simplified Johnson-Cook model) that consider the strain-rate effects on the material's behaviour are compared. For each material model three parameters were estimated on the basis of the impact experiment by using the explicit dynamic simulations combined with a parameter factorization according to the Taguchi array.

The Cowper-Symonds (C-S) material model with a bilinear characteristic is determined with the following parameters ([16] and [17]): elastic modulus $E$, Poisson's number $v$, tangent modulus $E_{t}$, hardening coefficient $\beta$, material density $\rho$, and the parameters $C$ and $P$ that describe the dependency of the yield stress $\sigma_{y}$ on the strain rate $\dot{\varepsilon}$, see Eq. (1). Therefore, the flow stress is calculated as follows:

$$
\begin{aligned}
& \sigma_{\text {flow }}=\sigma_{y}+E_{t} \cdot \varepsilon_{e f f}^{p}= \\
& =\left(\sigma_{0}+\beta \cdot \frac{E_{t} \cdot E}{E-E_{t}} \cdot \varepsilon_{e f f}^{p}\right) \cdot\left[1+\left(\frac{\dot{\varepsilon}}{C}\right)^{1 / P}\right]+E_{t} \cdot \varepsilon_{e f f}^{p} .
\end{aligned}
$$

For the C-S material model the strain rate influences only the yield stress $\sigma_{y}$. This means that the plastic curves (the flow stress as a function of strain) are parallel. The larger the strain rate, the higher the flow-stress curve, see Fig. 1a. For high-strain-rate applications the parameters $C$ and $P$ in Eqs. (1) and (3) are usually not estimated from the tensile test, due to the limitations of the existing tensile-test equipment (maximum strain rates are up to a few hundreds of $\mathrm{s}^{-1}$ ). Together with the tangent $E_{t}$ they were determined on the basis of the impact experiment.

Since the temperature effects were neglected in our case, the simplified Johnson-Cook (J-C) material model was applied with the parameter $m$ from Eq. (2) being equal to 0 . This material model is determined with the following parameters ([16] and [17]): elastic modulus $E$, Poisson's number $v$, reference yield stress $\sigma_{0}$, exponent of the flow-stress curve $n$, scale factor $B$ for the effective plastic strain, sensitivity $c$ to the logarithm of the strain rate and material density $\rho$. The flow stress is then given by: 

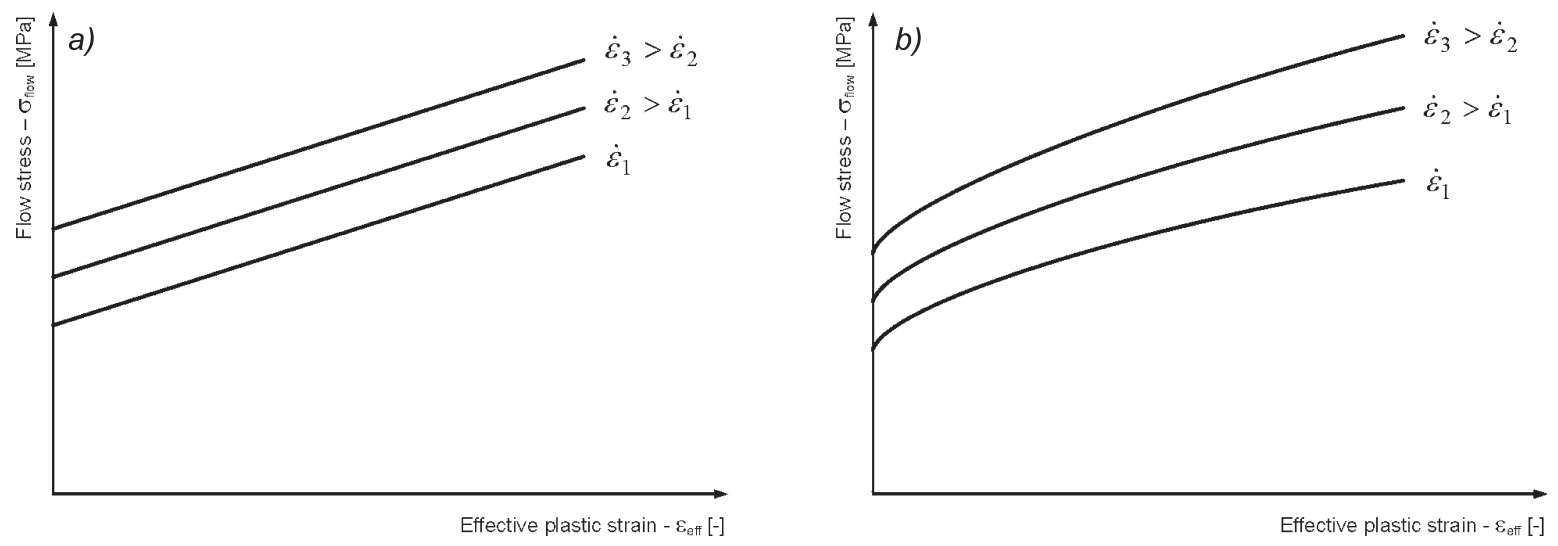

Fig. 1. Flow stress for a) the Cowper-Symonds material model and b) the Johnson-Cook material model

$$
\sigma_{\text {flow }}=\left[\sigma_{0}+B \cdot\left(\varepsilon_{\text {eff }}^{p}\right)^{n}\right] \cdot\left[1+c \cdot \ln \left(\frac{\dot{\varepsilon}^{p}}{\dot{\varepsilon}_{0}}\right)\right] .
$$

For the J-C material model the strain rate influences the flow stress $\sigma_{\text {flow }}$ in its whole range and the flow-stress curves are not parallel. Their nonlinearity depends on the exponent $n$. The larger the strain rate, the higher the flow-stress curve, see Fig. 1b. The three parameters $B, n$ and $c$ in Eq. (4) cannot be estimated from the tensile test and were determined from the impact experiment.

\subsection{Simulation Plan for Material-Parameter Estimation}

For each of the two strain-rate-dependent material models, three parameters (i.e., $E_{t}, C$ and $P$ for the C-S material model and $B, n$ and $c$ for the J-C material model) need to be determined. These parameters are usually determined using a reversed engineering approach with the help of numerical simulations that reproduce the actual experiment ([11], [12] and [18]). This means that a series of numerical simulations with different combinations of material parameters are carried out to establish which combination of material parameters best fits the experimental results. The problem is that the strain-rate-dependent parameters can be selected from a domain with a range that spans over many orders of magnitude.

For this reason it is almost impossible to run a full-factorial simulation plan to determine the optimal strain-rate-dependent parameters, because the processing time would be prohibitive even in the case when simulations are run on a supercomputer. To shorten the processing time for estimating the material parameters it was decided to apply orthogonal Taguchi arrays for a simulation-plan set-up. The reason for this decision was that the use of Taguchi arrays results in a significant reduction in the number of studied parameter combinations. Their advantage is that the assigned combinations of parameters are approximately equally distributed over the search space, which is not always the case with, e.g., Latin hyper-cubes.

We applied a $\mathrm{L}_{81}\left(3^{40}\right)$ Taguchi array and transformed it into the $\mathrm{L}_{81}\left(9^{10}\right)$ orthogonal array using the linear graph in Fig. 2 ([19] and [20]). This was done because we needed as many levels per parameter as possible and $\mathrm{L}_{81}(910)$ best suited this requirement.

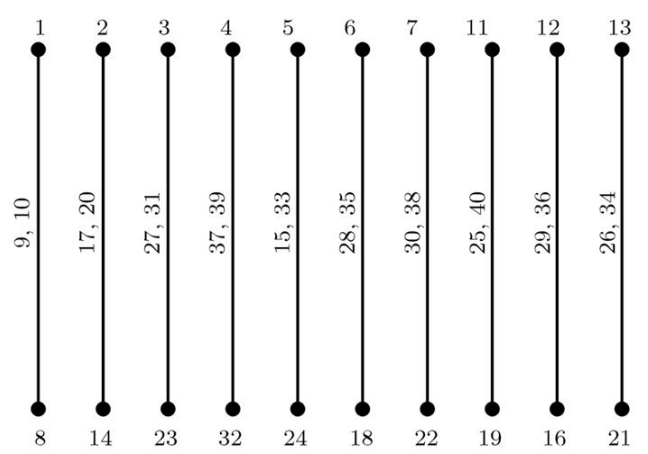

Fig. 2. Linear graph for the transformation of a $L_{81}(340)$ Taguchi array into a $L_{81}(910)$ array

Using the $\mathrm{L}_{81}\left(9^{10}\right)$ orthogonal array the three material parameters $\left(E_{t}, C\right.$ and $P$ for the C-S material model and $B, n$ and $c$ for the J-C material model) are attributed to the first three columns of the $\mathrm{L}_{81}(910)$ array. The levels were chosen from a very wide domain to account for all the possible parameter values for different kinds of steels. This makes the proposed approach general, although it was tested for the case of E185 steel. Since the ranges of the individual parameters span over more than one order 
of magnitude, the logarithms of these parameters represent the nine-level factors in the Taguchi array. In this manner 81 combinations of the parameter triples $\left(E_{t}, C, P\right)$ and $(B, n, c)$ were obtained that cover the whole domains of these parameters, see Fig. 3 for the parameters of the C-S material model and Fig. 4 for the parameters of the J-C material model.

Table 1. Parameters levels for the C-S material model

\begin{tabular}{ccccc}
\hline \multicolumn{5}{c}{ Original parameter levels of parameter $C\left[\mathrm{~ms}^{-1}\right]$} \\
\hline 0.2154 & 0.4642 & 1.0000 & 2.1544 & 4.6416 \\
\hline 10.0000 & 21.5443 & 46.4159 & 100.0000 \\
\hline \multicolumn{5}{c}{ Original parameter levels of parameter $P[-]$} \\
\hline 1.0000 & 1.7783 & 3.1623 & 5.6234 & 10.0000 \\
\hline 17.7828 & 31.6228 & 56.2341 & 100.0000 \\
\hline \multicolumn{5}{c}{ Original parameter levels of parameter $E_{t}[\mathrm{GPa}]$} \\
\hline 0.1000 & 0.1778 & 0.3162 & 0.5623 & 1.0000 \\
\hline 1.7783 & 3.1623 & 5.6234 & 10.0000 \\
\hline \multicolumn{5}{c}{} \\
\hline
\end{tabular}

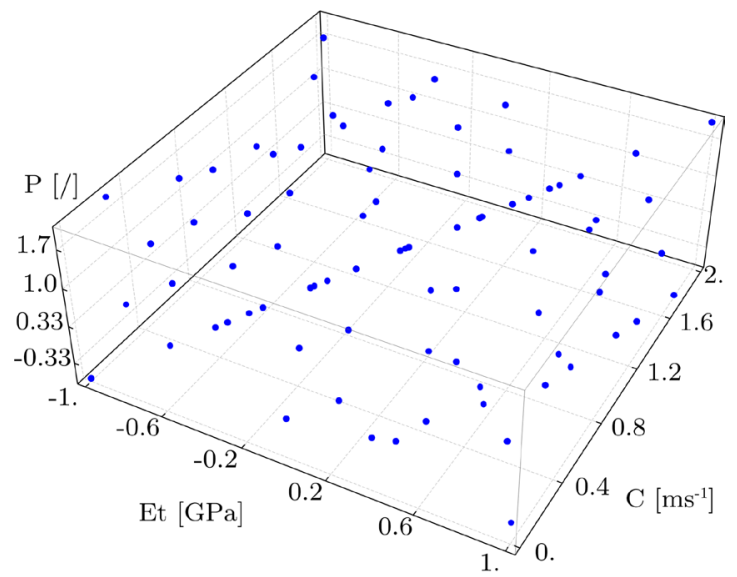

Fig. 3. Distribution of C-S material-parameter combinations over their domains

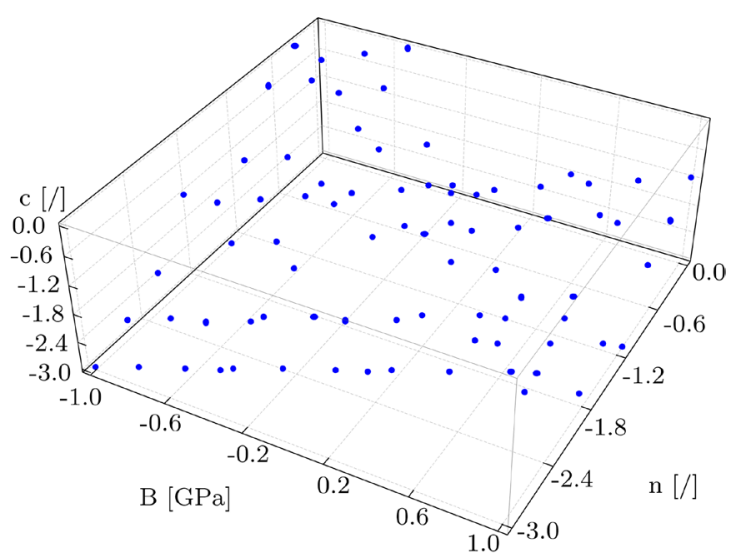

Fig. 4. Distribution of J-C material-parameter combinations over their domains
By applying the Taguchi arrays for the simulation plan the number of material-parameter combinations that need to be simulated was reduced by a factor of nine when compared to the full-factorial simulation plan.

Table 2. Parameter levels for the J-C material model

\begin{tabular}{|c|c|c|c|c|}
\hline \multicolumn{5}{|c|}{ Original parameter levels of parameter $B$ [GPa] } \\
\hline 0.1000 & 0.1778 & 0.3162 & 0.5623 & 1.0000 \\
\hline 1.7783 & 3.1623 & 5.6234 & 10.0000 & \\
\hline \multicolumn{5}{|c|}{ Original parameter levels of parameter $n[-]$} \\
\hline 0.001 & 0.0024 & 0.0056 & 0.0133 & 0.0316 \\
\hline 0.0750 & 0.1778 & 0.4217 & 1.0000 & \\
\hline \multicolumn{5}{|c|}{ Original parameter levels of parameter $c[-]$} \\
\hline 0.001 & 0.0024 & 0.0056 & 0.0133 & 0.0316 \\
\hline 0.0750 & 0.1778 & 0.4217 & 1.0000 & \\
\hline
\end{tabular}

For each combination of the material parameters six numerical simulations were carried out to account for the six different boundary and initial conditions, see Table 3. Therefore, when applying the simulation plan according to the $\mathrm{L}_{81}(910)$ Taguchi array $81 \cdot 6=486$ numerical simulations were performed for each of the two material models.

A cost function that measures the deviations of the experimental and simulation results was defined so that it measured the difference between the experimentally determined and simulated data for the indentation depth $H$ and the position of the indentation centre $Z$ for the specimen. The averages of the experimentally determined values for these two geometrical parameters for two specimen thicknesses and three different velocities of the ball are listed in Table 3. The cost function that was used to assess the goodness-of-fit between the experiments and the simulations is defined as follows for the C-S and J-C material models:

$$
\begin{aligned}
& f\left(E_{t}, P, C\right)=\frac{1}{k}\left(\begin{array}{l}
w_{H} \cdot \sum_{i=1}^{k}\left(H_{\text {exp }}-H_{\text {sim }}\right)^{2}+ \\
+\left(1-w_{H}\right) \cdot \sum_{i=1}^{k}\left(Z_{\text {exp }}-Z_{\text {sim }}\right)^{2}
\end{array}\right), \\
& f(B, n, c)=\frac{1}{k}\left(\begin{array}{l}
w_{H} \cdot \sum_{i=1}^{k}\left(H_{\text {exp }}-H_{\text {sim }}\right)^{2}+ \\
+\left(1-w_{H}\right) \cdot \sum_{i=1}^{k}\left(Z_{\text {exp }}-Z_{\text {sim }}\right)^{2}
\end{array}\right),
\end{aligned}
$$

where $k$ is the number of experimental results with different boundary and initial conditions (according to Table $3, k=6$ ). $H_{\text {exp }}$ and $Z_{\text {exp }}$, are the averaged 
measured maximum indentation depth and its $z$ coordinate for the specimen. $H_{\text {sim }}$ and $Z_{\text {sim }}$ are the maximum indentation depth and its $z$ coordinate for the specimen obtained by simulations. $w_{H}$ was a weighting factor in the two cost functions and was equal to 0.5 in our case.

\section{EXPERIMENTAL ARRANGEMENT}

\subsection{Measurement of a Static Stress-Strain Curve}

The methodology that was described in Section 1 was applied to characterise the strain-rate-dependent material behaviour of a mild steel E185. Its static material properties (elastic modulus, yield stress, ultimate tensile stress) were measured according to the ASTM E8/E8M standard [21] on Zwick/Roell Z050 testing equipment.
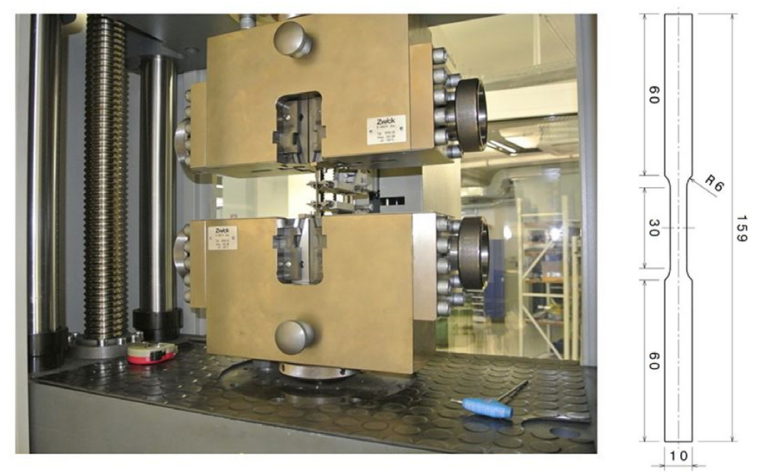

Fig. 5. Zwick/Roell Z050 test stand and the specimen

The test stand and the specimen geometry are presented in Fig. 5. A total of 21 specimens were tested. The average yield stress and the ultimate tensile strength were $185 \mathrm{MPa}$ and $350 \mathrm{MPa}$, respectively.
The measured engineering stress-strain curves are presented in Fig. 6a and the resulting average truestress-true-strain curve is presented in Fig. 6b. This true-stress-true-strain curve was determined with Eqs. (6) and (7), see Dowling [22].

$$
\begin{gathered}
\tilde{\varepsilon}=\ln (1+\varepsilon), \\
\tilde{\sigma}=\sigma(1+\varepsilon) .
\end{gathered}
$$

$\varepsilon$ and $\sigma$ were the corresponding average engineering strain and stress, respectively.

\subsection{Experimental Determination of the Material Behaviour at High Strain Rates}

The main objective was to determine the strain-ratedependent material parameters for simulating the behaviour of a mild-steel sheet metal that is used as a shield during a turbine burst test. To identify the corresponding material parameters we designed experimental apparatus for shooting a steel ball at a flat specimen. The experimental arrangement was based on the ASTM D5420 standard [23], which describes a test method for measuring the impact resistance of a flat rigid plastic specimen by means of a striker impacted by a falling weight. During the impact between the ball and the flat specimen strains can be measured on the left-hand side of the specimen with strain gauges. After the impact test the gross geometric data, i.e., the indentation depth $H$ and the position of the indentation centre $Z$, were measured, see Fig. 7.

The experimental apparatus was mounted on a testing machine that was originally built for burst tests on supercharger structures, see Fig. 7.
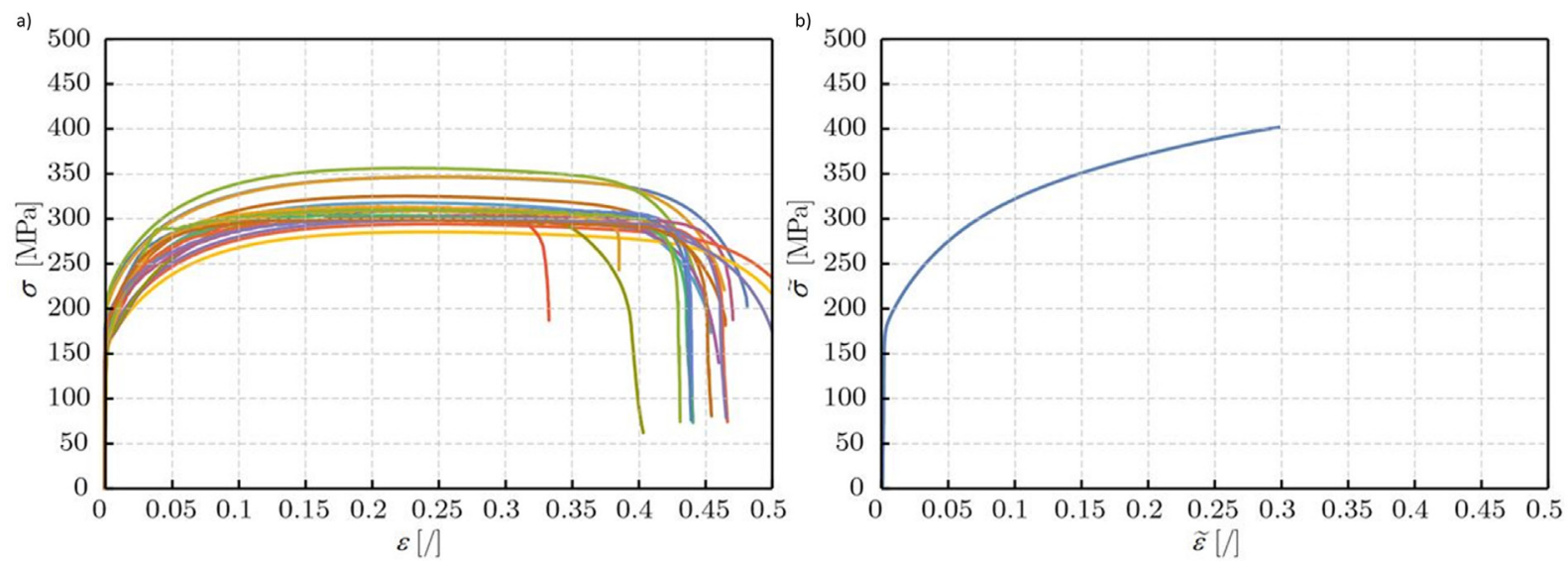

Fig. 6. a) Measured engineering stress-strain curves; and b) the resulting true-stress-true-strain curve 


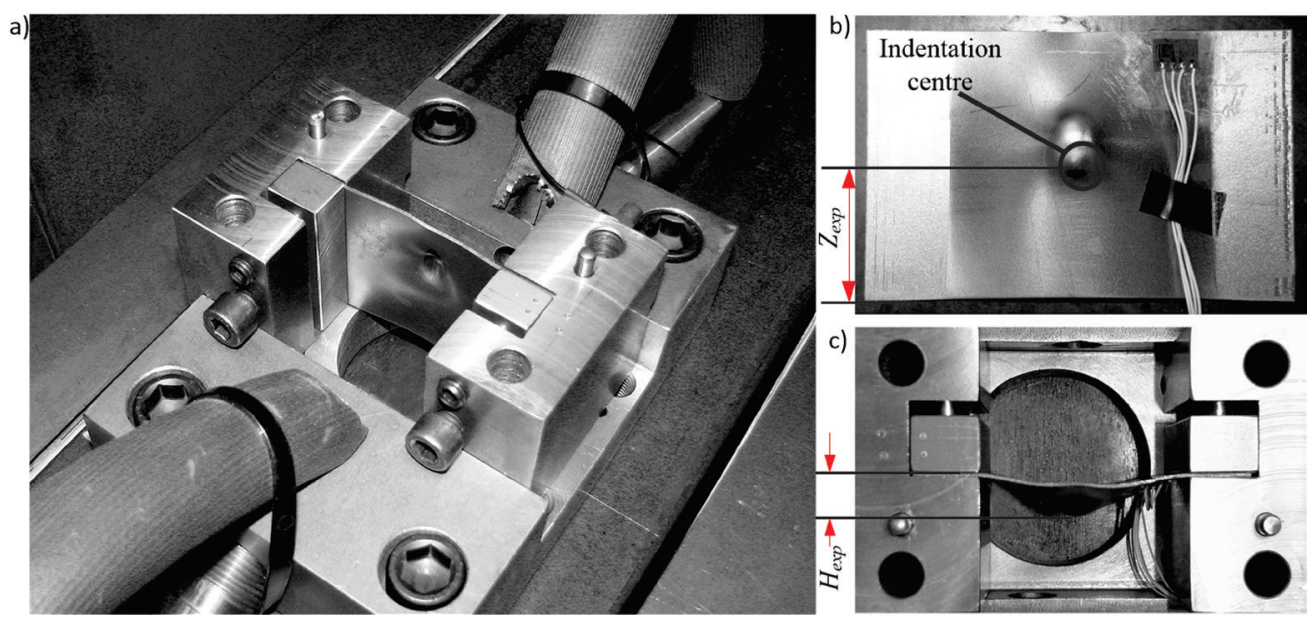

Fig. 7. a) An experimental device; b) front view and c) upper view of the experimental specimen

To study the different dynamic behaviours of steel plates with different thicknesses, balls with a diameter of $12 \mathrm{~mm}$ and a weight of $7 \mathrm{~g}$ were shot at the centre of the specimens at an angle of $20^{\circ}$ with different velocities that depended on the specimen thickness, see Table 3. The initial conditions and the plate thicknesses where chosen with regard to the machine's limitations and the expected application of the results (thin-shelled supercharger burst shield). The specimens (see Fig. 7) were metal plates with dimensions of $98 \mathrm{~mm} \times 60 \mathrm{~mm}$. Two different sheetmetal thicknesses were tested: $1 \mathrm{~mm}$ and $1.5 \mathrm{~mm}$. The specimens were fixed along the shorter side. The free area of the specimen was $60 \mathrm{~mm} \times 60 \mathrm{~mm}$. The impact velocities were measured on the testing machine just before the impact point using photo-sensors. For each combination of the steel-plate thickness and the impact velocity, three test repetitions were usually performed. The average and the standard deviation of the indentation depth and the position of the indentation centre are presented in Table 3. Some of the plate specimens were also equipped with strain gauges for measuring the strains to obtain the strain rates. Such specimen preparation was time consuming and there were only a few specimens for which the strain gauges did not break off during the measurements. Nevertheless, some strain measurements were successful and an agreement between the measured and simulated strain rates for the 1-mm-thick plate and the impact velocity of $109 \mathrm{~m} / \mathrm{s}$ was as follows: the measured peak strain rate was approximately $160 \mathrm{~s}^{-1}$, whereas the simulated values at that spot were $200 \mathrm{~s}^{-1}$ to $250 \mathrm{~s}^{-1}$. The major causes for the difference of $30 \%$ were the idealisation of the FE model and the FE mesh resolution, since the strain-rate decay from the impact point to the border is progressive and it is difficult to calculate the true strain-rate value at the spot of the strain gauges. The simulated peak strain rate at the impact point was $5000 \mathrm{~s}^{-1}$.

Table 3. Combinations of boundary conditions and results from experiments

\begin{tabular}{ccccc}
\hline $\begin{array}{c}\text { Experiment } \\
\text { condition } \\
\text { number }\end{array}$ & $\begin{array}{c}\text { Specimen } \\
\text { thickness } \\
{[\mathrm{mm}]}\end{array}$ & $\begin{array}{c}\text { Average } \\
\text { ball } \\
\text { velocity } \\
{[\mathrm{m} / \mathrm{s}]}\end{array}$ & $\begin{array}{c}\text { Measured max. } \\
\text { indentation } \\
\text { depth, average, } \\
H_{\text {exp }}[\mathrm{mm}]\end{array}$ & $\begin{array}{c}\text { Position of } \\
\text { the max. } \\
\text { indentation } \\
\text { depth, average, } \\
Z_{\text {exp }}[\mathrm{mm}]\end{array}$ \\
\hline 1 & 1 & 103 & 11.37 & 34.83 \\
\hline 2 & 1 & 109 & 12.12 & 34.89 \\
\hline 3 & 1 & 121 & 13.07 & 35.11 \\
\hline 4 & 1.5 & 121 & 10.38 & 30.19 \\
\hline 5 & 1.5 & 131 & 11.53 & 29.60 \\
\hline 6 & 1.5 & 139 & 12.65 & 30.49 \\
\hline
\end{tabular}

From the results in Table 3 we can see that the scatter of the experimental results is relatively small, which means that the experimental arrangement was appropriate for our study. Furthermore, we can see that the indentation depth increases with the increasing velocity. The indentation depth at a thickness of 1.5 $\mathrm{mm}$ is smaller than for the 1-mm-thick steel plate. Besides, it is clear from Table 3 that for the $1.5-\mathrm{mm}$ thick specimens, the point with the deepest indentation is approximately $30 \mathrm{~mm}$ from the lower side of the specimen, just in the centre of the impact. This is not the case for the 1-mm-thick specimens, for which the point with the largest indentation is $5 \mathrm{~mm}$ from the centre of the impact. The lack of displacement of the deepest imprint for the thicker plate is a consequence of the fact that after the plastification almost all of the kinetic energy of the ball was consumed. This was not 
the case for the thinner plate and the ball proceeded in its direction of travel, though causing an extension of the imprint in the vertical direction. This implies different impact dynamics for the specimens with different thicknesses and this should be replicated by the numerical simulations if the strain-rate-dependent material parameters are properly identified.

\section{RESULTS AND DISCUSSION}

\subsection{FE Model for Identification of the Material Parameters}

The LS-DYNA explicit dynamic FE code was used to identify the material parameters of the C-S and J-C material models [16]. The FE model that was used to simulate the ball-impact experiment from Section 2 is presented in Fig. 8. The steel sheet model had 5436 four-node and three-node shell finite elements. The mesh density around the impact area was larger than in the wider region of the specimen model, to accurately simulate the indentation. The mesh density was chosen to optimise the processing time for a reasonable accuracy of the deformation. The rigid ball was modelled with 448 solid finite elements. In the finite-element model, the nodes on both sides of the thin sheet-metal plate were fixed (Fig. 8). A rigid ball was shot into the centre of the sheet at an angle of $20^{\circ}$ with different impact velocities, which are presented in Table 3.

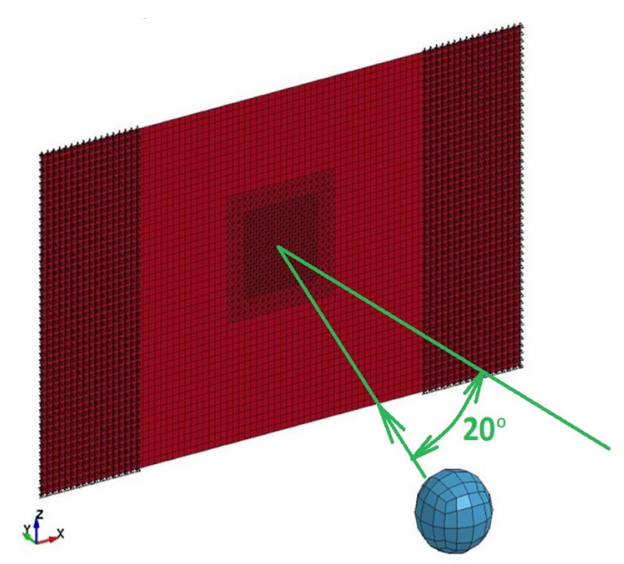

Fig. 8. FE model for a ball-plate impact simulation

Between the flat specimen and the rigid ball was an AUTO_SURFACE_TO_SURFACE contact with the friction coefficient $\mu=0.2$. This was an approximate average value from different references [24] and [25]. During the simulation, a strain at the left-hand side of the sheet and the gross geometric dimensions of the specimen were recorded for further processing, like in the experiment (Fig. 7).

The C-S material model was applied using the MAT PLASTIC KINEMATIC (MAT3) material model from LS-DYNA ([16] and [17]). This material model is defined with the following parameters, see also Eqs. (1) and (3): material density, elastic modulus, Poisson's ratio, yield stress $\sigma_{0}$, tangent modulus $E_{t}$ and the C-S parameters $P$ and $C$. The parameters $E_{t}, P$ and $C$ were estimated using the procedure from Section 1 and the above-described FE model.

The J-C material model was applied using the MAT_SIMPLIFIED_JOHNSON_COOK (MAT98) material model from LS-DYNĀ ([16] and [17]). This material model is defined with the following parameters, see also Eq. (2): material density, elastic modulus, Poisson's ratio, yield stress $\sigma_{0}$, and the J-C parameters $B, n$ and $c$. The latter three parameters were estimated using the procedure from Section 1 and the above-described FE model.

The values of the other material parameters were fixed in our simulation: the material density was 7850 $\mathrm{kg} / \mathrm{m}^{3}$, the elastic modulus was $2.1 \cdot 10^{5} \mathrm{~N} / \mathrm{mm}^{2}$, the yield stress was $\sigma_{0}=185 \mathrm{MPa}$ (see Fig. 6) and the Poisson's ratio was $v=0.3$. The reference strain rate $\dot{\varepsilon}_{0}$ for the J-C model was $1 \mathrm{~s}^{-1}$ and was taken as a default value from LS-DYNA. This value usually follows from the tensile-test arrangement. However, its choice does not phenomenologically influence the results, since the variation of the parameter $\dot{\varepsilon}_{0}$ monotonically influences the changes of the estimated parameter $c$ :

$$
\frac{C_{1}}{C_{2}}=\ln \frac{\dot{\varepsilon}_{0}^{(1)}}{\dot{\varepsilon}_{0}^{(2)}} .
$$

\subsection{Results and Discussion}

Table 1 and Fig. 3 represent factor levels for the original domains of the C-S parameters $E_{t}, P$ and $C$. Table 2 and Fig. 4 represent factor levels for the original domains of the J-C parameters $B, n$ and $c$. For each of the 81 combinations of the three material parameters for the C-S and J-C material models six simulations were carried out, i.e. three different impact velocities combined with two different specimen thicknesses. The FE simulations were carried out on a numerical server with two Intel Xeon X5670 2.93-GHz processors, 48 GB of RAM and a Linux operating system. The time spent for one numerical simulation on one processor's core was about 2 hours.

The values of the cost function from Eq. (5a) for the C-S material model are presented in Fig. 9. The values of the cost function from Eq. (5b) for 
the J-C material model are presented in Fig. 10. In both diagrams the logarithms of the cost functions from Eqs. (5a) and (5b) are presented. The best three combinations of the C-S parameters $E_{t}, P$ and $C$ and the J-C parameters $B, n$ and $c$ are listed in Table 4 .

We can see from Fig. 9 and Table 4 that the best combinations of the C-S parameters $E_{t}, P$ and $C$ are in the middle at the top of the original domain. The best combinations of the J-C parameters $B, n$ and $c$ are on the right of the original domains, see Fig. 10 and Table 4. The parameter combinations with the worst cost-function values failed to reproduce, in particular the position of the maximum indentation depth during simulations.

If we look at the results for both material models, we can conclude that the optimal values of the individual parameters can be up to two orders of magnitude distant from each other. This means that the ranges for the original domains of both the C-S and $\mathrm{J}-\mathrm{C}$ parameter triples were too wide for a reliable estimation of these parameters. For this reason we decided to narrow the ranges of the $\mathrm{C}-\mathrm{S}$ and $\mathrm{J}-\mathrm{C}$ parameter domains around their most promising values from Table 4. This was followed by a new simulation plan that was again composed with the help of the $\mathrm{L}_{81}\left(9^{10}\right)$ Taguchi array, but with the $E_{t}, P$, $C$ and $B, n, c$ parameter levels taken for the narrowed domains in the same manner as was the case for the original domain. The narrowed domains were as follows: (i) for the C-S material model: $C=10 \mathrm{~ms}^{-1}$ to $46.4159 \mathrm{~ms}^{-1}, P=3.1623$ to 10 and $E_{t}=0.5623 \mathrm{GPa}$ to $1.7783 \mathrm{GPa}$; (ii) for the J-C material model: $B=$ $0.1778 \mathrm{GPa}$ to $3.1623 \mathrm{GPa}, n=0.1778$ to 1 and $c=$ 0.005623 to 0.1778 .

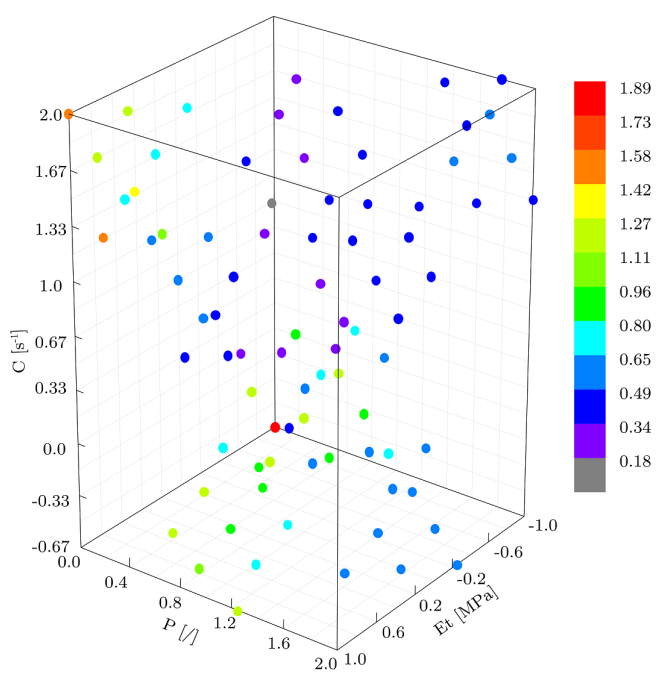

Fig. 9. Cost-function values for the original domains of the Cowper-Symonds parameters

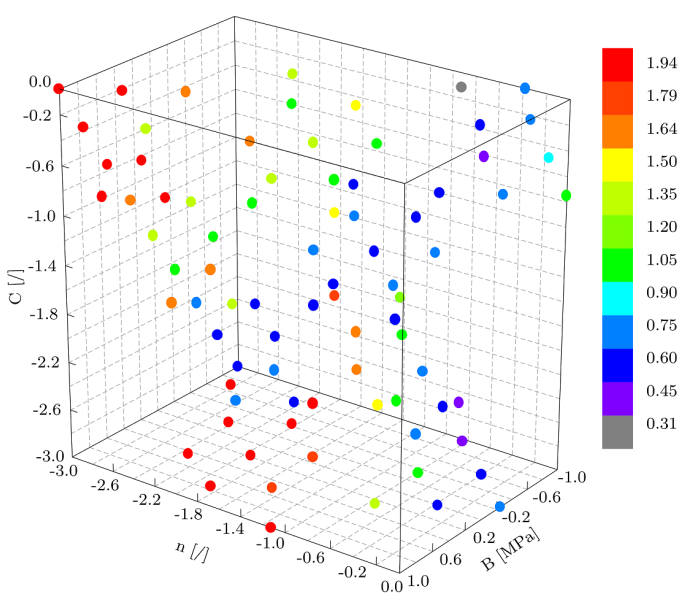

Fig. 10. Cost-function values for the original domains of the Johnson-Cook parameters

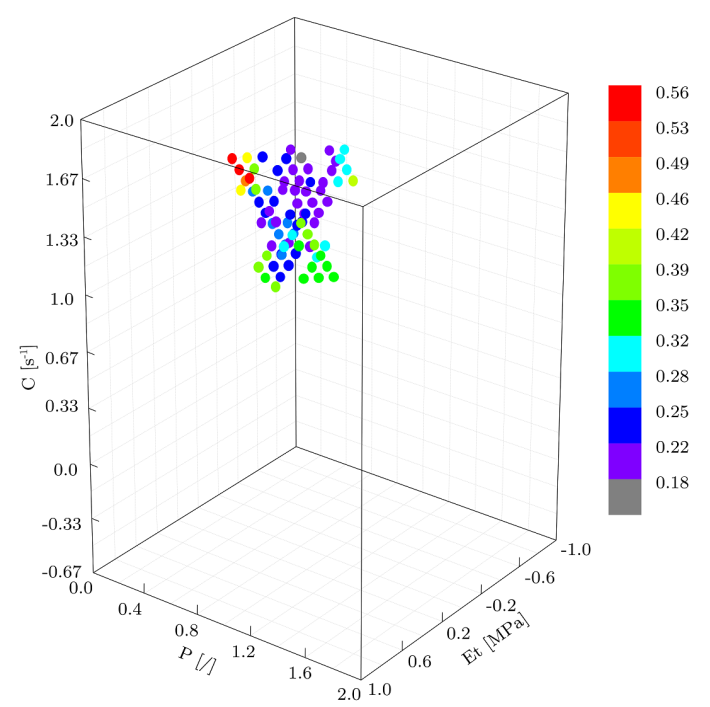

Fig. 11. Cost-function values for the narrowed domains of the Cowper-Symonds parameters

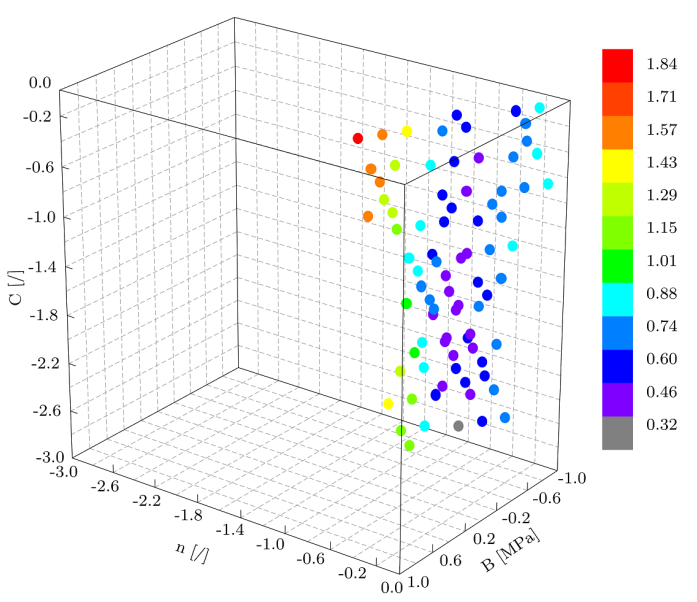

Fig. 12. Cost-function values for the narrowed domains of the Johnson-Cook parameters 
We actually performed a "nested" Taguchi simulation plan in the second phase of the simulations.

The resulting distributions of cost-function values for the narrowed domains are presented in Fig. 11 for the C-S parameters and in Fig. 12 for the $\mathrm{J}-\mathrm{C}$ parameters. The best three combinations of the C-S parameters $E_{t}, P$ and $C$ and the J-C parameters $B, n$ and $c$ for the narrowed domains are much closer together when compared to the original domains for those parameters. The average values from the three best solutions are listed in Table 5. We can conclude from Table 5 that our estimations of the parameters $E_{t}$, $P, C$ and $B, n, c$ are comparable to the values reported for mild steels in the literature ([9] to [11]), despite different experimental arrangements and the fact that the strain rates during the experiments were 10 or more times higher in our case. We can conclude that we obtained reasonable estimates of the parameters $E_{t}$, $P, C$ and $B, n, c$ for our case.

Plastic flow curves $\sigma-\varepsilon_{\text {eff }}^{p}$ for the two material models are presented in Fig. 13. They were calculated for different strain rates with the averaged parameters $E_{t}, P, C$ and $B, n, c$ from Table 5 . We can see from this figure that the estimates of the parameters for both material models were consistent, because the flow curves span a similar domain of the $\sigma-\varepsilon_{\text {eff }}^{p}$ space for the two material models.

From the results we can conclude that the described methodology, which combines the nested design with the FE simulations, can be very time efficient for estimating the parameters of material models that govern the material's behaviour at high strain rates. The added value of our approach is meaningful, especially in the cases when the number of parameters that need to be identified is relatively high, with a wide range of potential parameter values. With the Taguchi orthogonal array, a reasonable estimate of the material parameters can be found with a relatively small computing effort and a short time. For example, if we applied a methodology that is based on genetic algorithms and was originally developed for estimating the foam-material-model parameters [18], the processing times would be approximately 100-times longer. This would be appreciated if the numbers of parameters to be identified and the wide ranges were to be increased.

\section{CONCLUSIONS}

The article presents a general approach to estimating the parameters that govern a material's behaviour at high strain rates. In our approach the Taguchi experimental design was combined with the FE code LS-DYNA to estimate the material parameters using the results of the impact test between the ball and thin sheet metal. The presented approach was applied to the realistic case of a material-parameter estimation for two different material models, i.e., the C-S and the J-C material models.

Table 4. The best three combinations for the original domains of the $C$-S and J-C material parameters

\begin{tabular}{llcccc}
\hline & & Parameter $C\left[\mathrm{~ms}^{-1}\right]$ & Parameter $P[/]$ & Parameter $E_{t}[\mathrm{GPa}]$ & Cost-function value $[/]$ \\
\cline { 2 - 6 } $\begin{array}{l}\text { Cowper-Symonds } \\
\text { material model }\end{array}$ & Combination 1 & 21.5443 & 5.6234 & 1.0000 & 1.524 \\
\cline { 2 - 6 } & Combination 2 & 46.4159 & 10.000 & 1.0000 & 1.588 \\
\cline { 2 - 6 } & Combination 3 & 2.1544 & 3.1623 & 1.0000 & 1.826 \\
\hline \multirow{3}{*}{$\begin{array}{l}\text { Johnson-Cook } \\
\text { material model }\end{array}$} & Carameter $B[\mathrm{GPa}]$ & Parameter $n[/]$ & Parameter $c[/]$ & Cost-function value $[/]$ \\
\cline { 2 - 6 } & Combination 1 & 0.1778 & 0.1778 & 1.0000 & 2.020 \\
\cline { 2 - 6 } & Combination 2 & 0.5623 & 0.4217 & 0.0056 & 2.259 \\
\hline
\end{tabular}

Table 5. The average of the best three combinations for the narrowed domains of the C-S and J-C material parameters

\begin{tabular}{|c|c|c|c|c|c|}
\hline \multirow{5}{*}{$\begin{array}{l}\text { Cowper-Symonds } \\
\text { material model }\end{array}$} & & Parameter $C$ [ms-1] & Parameter $P[/]$ & Parameter $E_{t}[\mathrm{GPa}]$ & Cost-function value [/] \\
\hline & Our average & 41.0133 & 6.2000 & 0.9550 & 1.522 \\
\hline & Belingardi et al. [12] & $3.006-4.987$ & $1.329-1.619$ & - & - \\
\hline & Marais et al. [10] & 2.000 & 5.000 & - & - \\
\hline & Markiewicz et al. [11] & 1.150 & 7.750 & - & - \\
\hline \multirow{4}{*}{$\begin{array}{l}\text { Johnson-Cook } \\
\text { material model }\end{array}$} & & Parameter $B$ [GPa] & Parameter $n[/]$ & Parameter $c$ [/] & Cost-function value [/] \\
\hline & Our average & 1.9250 & 0.8183 & 0.0972 & 2.138 \\
\hline & Singh et al. [9] & $0.779-2.692$ & $0.743-0.928$ & $0.0144-0.021$ & - \\
\hline & Marais et al. [10] & 0.292 & 0.310 & 0.025 & - \\
\hline
\end{tabular}


It turned out that it is possible to obtain reliable estimates of the C-S parameters $\left(E_{t}, P, C\right)$ and $\mathrm{J}-\mathrm{C}$ parameters $(B, n, c)$ with a nested design-of-simulation approach using only two iteration runs. The materialparameter estimates for the two models are consistent and comparable to the results from the literature.
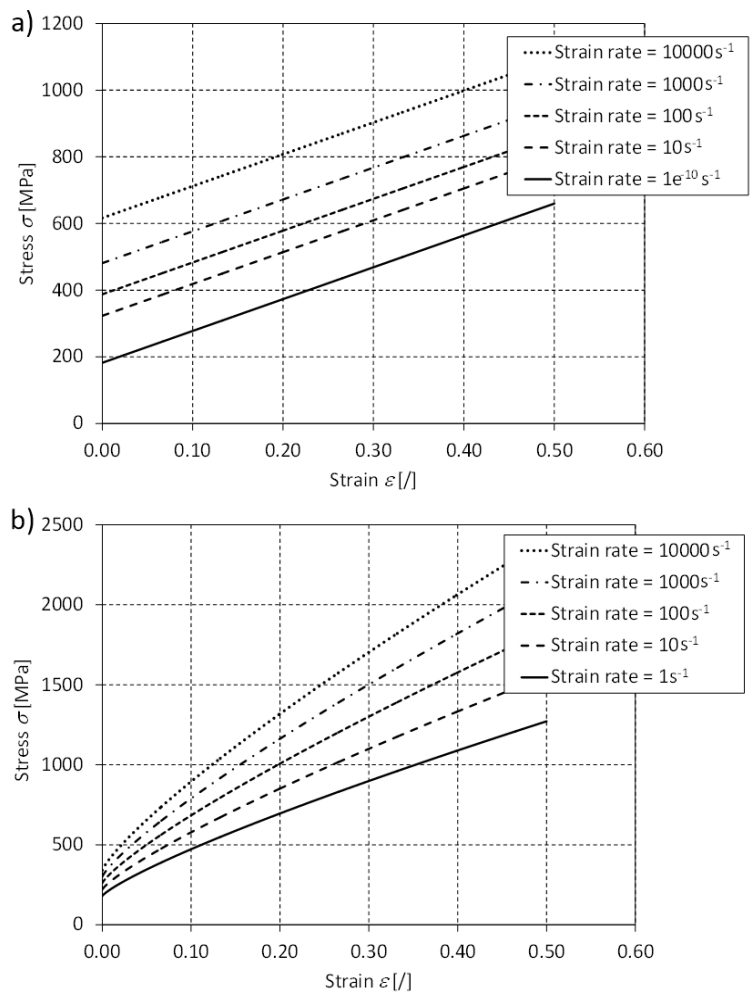

Fig. 13. Plastic flow curves for different strain rates (in s-1) for a) the Cowper-Symonds, and b) the Johnson-Cook material models

\section{REFERENCES}

[1] Meyers, M.A. (1994). Dynamic Behavior of Materials. John Wiley \& Sons, New York, D0l:10.1002/9780470172278.

[2] Armstrong, R.W., Walley, S.M. (2008). High strain rate properties of metals and alloys. International Materials Reviews, vol. 53, no. 3, p. 105-128, Dol:10.1179/174328008X277795.

[3] Johnson, G.R., Cook, W.H. (1983). A constitutive model and data for metals subjected to large strains, high strain rates and high temperatures. Proceedings of the $7^{\text {th }}$ International Symposium on Ballistics.

[4] El-Magd, E. (1994). Mechanical properties at high strain rates. Le Journal de Physique IV, vol. 4, no. C8, p. 149-170, DOl:10.1051/jp4:1994823.

[5] Zhao, H., Gary, G. (1996). The testing and behaviour modelling of sheet metals at strain rates from 10-4 to $104 \mathrm{~s}-1$. Materials Science and Engineering: A, vol. 207, no. 1, p. 46-50, DOI:10.1016/0921-5093(95)10017-2.
[6] Huh, H., Kim, S.B., Song, J.H., Yoon, J.H., Lim, J.H., Park, S.H. (2009). Investigation of elongation at fracture in a high speed sheet metal forming process. Steel Research International, vol. 80, no. 5, p. 316-322.

[7] Huh, H., Lim, J.H., Park, S.H. (2009). High speed tensile test of steel sheets for the stress-strain curve at the intermediate strain rate. International Journal of Automotive Technology, vol. 10, no. 2, p. 195-204, D0l:10.1007/s12239-009-0023-3.

[8] Kim, S.B., Hoon, H. (2008). Evaluation of the failure elongation of steel sheets for an auto-body at the intermediate strain rate. Key Engineering Materials, vol. 385-387, p. 749-752, DOl:10.4028/www.scientific.net/kem.385-387.749.

[9] Singh, N.K., Cadoni, E., Singha, M.K., Gupta, N.K. (2013). Mechanical behavior of a structural steel at different rates of loadings. Proceedings of the International Symposium on Engineering under Uncertainty: Safety Assessment and Management, p. 859-868, Dol:10.1007/978-81-322-07573_57.

[10] Marais, S.T., Tait, R.B., Cloete, T.J., Nurick, G.N. (2004). Material testing at high strain rate using the split Hopkinson pressure bar. Latin American Journal of Solids and Structures, vol. 1, no. 3, p. 219-339.

[11] Markiewicz, E., Ducrocq, P., Drazetic, P. (1998). An inverse approach to determine the constitutive model parameters from axial crushing of thin-walled square tubes. International Journal of Impact Engineering, vol. 21, no. 6, p. 433-449, DOI:10.1016/S0734-743X(98)00004-9.

[12] Belingardi, G., Chiandussi, G., Ibba, A. (2006). Identification of strain-rate sensitivity parameters of steel sheet by genetic algorithm optimisation. Brebbia, C.A. (ed), High Performance Structures and Materials III. WIT Press, Wessex Institute of Technology, p. 201-210, D0I:10.2495/HPSM06021.

[13] Rule, W.K. (1997). A numerical scheme for extracting strength model coefficients from Taylor test data. International Journal of Impact Engineering, vol. 19, no. 9-10, p. 797-810, DOl:10.1016/S0734-743X(97)00015-8.

[14] Kurtaran H., Buyuk, M., Eskandarian, A., (2003). Ballistic impact simulation of GT model vehicle door using finite element method. Theoretical and Applied Fracture Mechanics, vol. 40, no. 2, p. 113-121, Dol:10.1016/S01678442(03)00039-9.

[15] Schwer, L.E., Hacker, K., Poe, K. (2006). Perforation of metal plates: laboratory experiments and numerical simulations. Proceedings to the 9th Annual LS DYNA Users Conference.

[16] Hallquist, J.0. (1998). LS-DYNA Theoretical Manual, Livermore Software Technology Corporation, Livermore.

[17] Hallquist, J.0. (2007). LS-DYNA Keyword User's Manual Version 971, Livermore Software Technology Corporation, Livermore.

[18] Škrlec, A., Klemenc, J., Fajdiga, M. (2014). Parameter identification for a low-density-foam material model using numerical optimisation procedures. Engineering Computations, vol. 31, no. 7, p. 1532-1549, D0l:10.1108/EC03-2013-0100.

[19] Taguchi, G. (1987). System of Experimental Design: Engineering Methods to Optimize Quality and Minimize Costs, Vol. 1. American Supplier Institute, Dearborn. 
[20] Taguchi, G. (1987). System of Experimental Design: Engineering Methods to Optimize Quality and Minimize Costs, Vol. 2. American Supplier Institute, Dearborn.

[21] ASTM E8/E8M-09. 2010. Standard test methods for tension testing of metallic materials. ASTM International. West Conshohocken, DOl:10.1520/E0008_E0008M-09.

[22] Dowling, N.E. (1993). Mechanical behavior of materials: Engineering Methods for Deformation, Fracture, and Fatigue. Prentice-Hall Inc., Englewood Cliffs.
[23] ASTM D5420-10. 2010. Standard Test Method for Impact Resistance of Flat, Rigid Plastic Specimen by Means of a Striker Impacted by a Falling Weight (Gardner Impact). ASTM International. West Conshohocken, Dol:10.1520/D5420-10.

[24] Wittel, H. (2009). Roloff/Matek Maschinenelemente: Tabellenbuch, Vieweg\&Teubner, Wiesbaden.

[25] Klemenc, J., Wagner, A., Grubisic, V., Fajdiga, M. (2011). Schienenzustand und Gleitreibungszahl zwischen Rad und Schiene. ETR, vol. 60, no. 11, p. 34-38. 